\title{
Textile allergic contact dermatitis caused by occupational exposure-An overlooked condition
}

\section{Rita Ramos Pinheiro ㄴ | Ana S. Borges $₫$ | Ana Brasileiro}

Department of Dermatology, Centro Hospitalar de Lisboa Central, Lisbon, Portugal

Correspondence

Rita Ramos Pinheiro MD, Alameda Santo António dos Capuchos, 1169-50 Lisboa, Portugal.

Email: rita.ramos.pinheiro@gmail.com

KEYWORDS: Acid Yellow, Basic Red, case report, occupational dermatitis, disperse dyes, Disperse Orange, hand eczema, textile contact dermatitis

Textile contact dermatitis is not uncommon. ${ }^{1}$ Disperse dyes used for colouring synthetic textiles (polyester, nylon, and fibre mixtures) are among the main culprits. They only partially bind to textile fibres, which may explain their sensitization properties.

\section{CASE REPORT}

A 66-year-old male presented with a 2-year history of severe hand eczema (Figure 1A), with a chronic, progressively worsening course. Intensive topical and oral therapy (with clobetasol ointment and prednisone, respectively) yielded little relief. There was no history of previous dermatological conditions, including eczema elsewhere. The patient denied previous hair dyeing or tattooing. He routinely wore cotton underwear. The patient had worked as a manager of a textile shop since the age of 30 years. Three years before the consultation, he changed his workplace in terms of directly attending customers at the store.

Work-related contact dermatitis was suspected, and the patient was patch tested with the Portuguese Contact Dermatitis Group baseline series, supplemented with a textile dye series comprising 16 disperse dyes. Patch test preparations were supplied by Bial Aristegui (Bilbao, Spain), and were applied with 8-mm Finn Chambers (Epitest, Tuusula, Finland) and fixed with Scanpor tape. Readings were performed on day (D) 3 and D7, according to European guidelines. ${ }^{2}$ Positive reactions were observed to $p$-phenylenediamine (PPD), caine mix, $p$-aminoazobenzene, Disperse Orange 1 and 3, Basic Red 46 and Acid Yellow 36 on D3 (Figure 1B,C) and D7. Moreover, exacerbation 


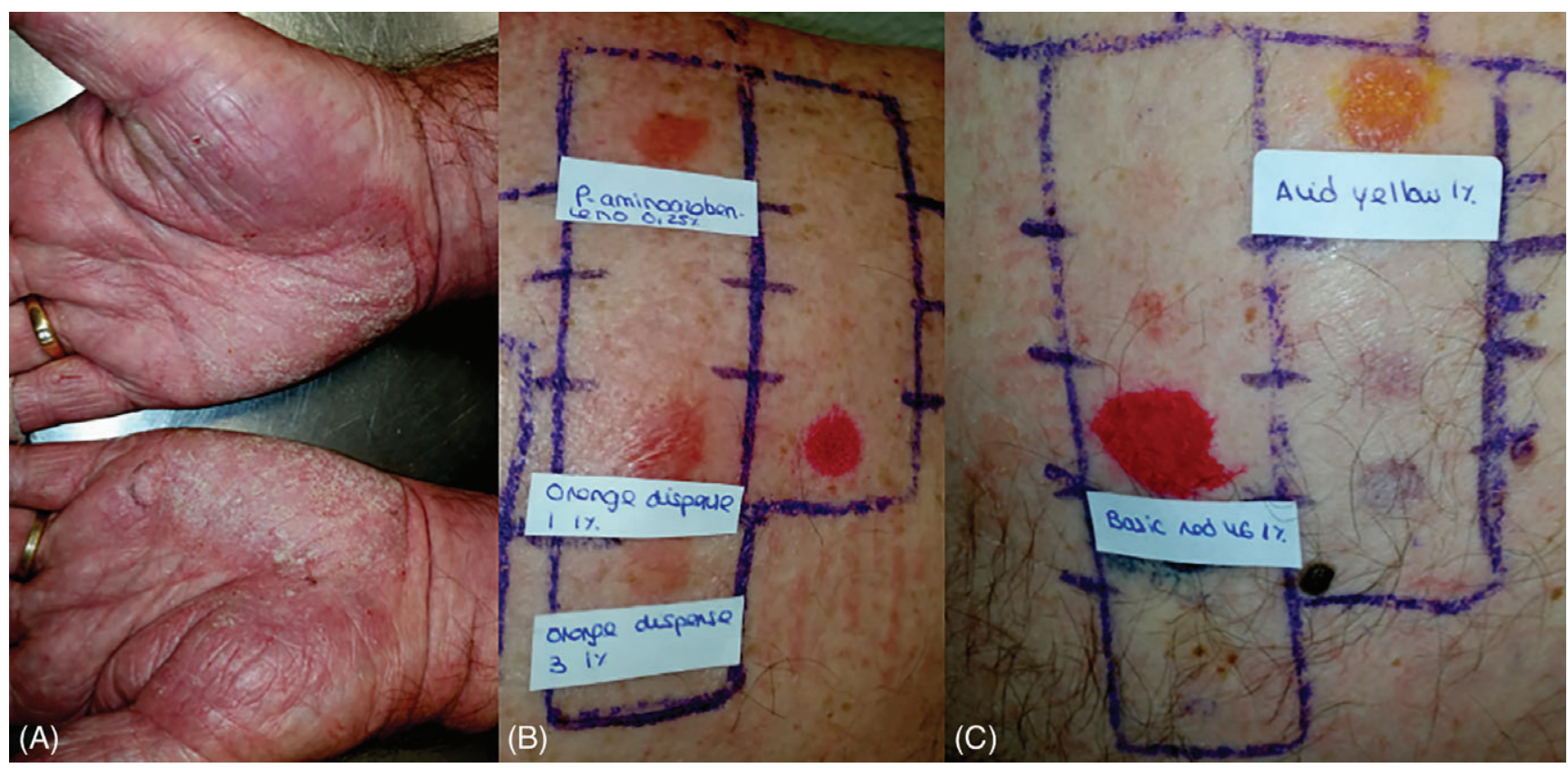

FIGURE 1 (A), On examination, the patient showed lichenified erythematous plaques on both palms associated with fissuring and scaling. Pruritus and pain secondary to fissuring were intense. (B, C), On day 3, strong positive reactions (++) to $p$-aminoazobenzene $0.25 \%$ wt/wt (pet.), Disperse Orange 1 and 3 1.0\% wt/wt (pet.), Basic Red 46 1.0\% wt/wt (pet.) and Acid Yellow 36 1.0\% wt/wt (pet.) were observed. On day 7, all reactions were classified as extreme positive $(+++)$, on the basis of intense erythema, infiltration, and coalescing vesicles

of hand dermatitis was observed during testing. The results suggested that sensitization to textile dyes was responsible for the chronic hand dermatitis. Positive reactions to PPD and caine mix were probably cross-reactions with Disperse Orange. The patient was advised to change work activities, avoiding direct contact with synthetic textiles. Complete resolution was observed after 2 months.

\section{DISCUSSION}

Our case highlights some particularities of textile contact dermatitis that may make diagnosis and management difficult. First, although textile contact dermatitis is typically described as a flexural dermatitis, ${ }^{1}$ it should also be suspected in other locations, especially when occupational dermatitis is suspected. Second, as a wide range of colours is obtained by mixing different disperse dyes, patients diagnosed with specific disperse dye contact allergy should generally avoid contact with synthetic fibres, regardless of their colour. ${ }^{1}$ Furthermore, in spite of European legislation, clothing labels do not precisely specify the disperse dyes used in production, which hampers the management of textile contact dermatitis patients. Natural fibres (linen, cotton, and wool) are coloured with chemically different dyes, and are recommended as alternatives.

Screening for textile contact dermatitis, with either a textile dye mix recently introduced into the European baseline series ${ }^{3}$ or 2 common disperse dyes, namely Disperse Orange 1 and Disperse Blue 106/124, as recommended by Portuguese Guidelines, ${ }^{4}$ seems to be important. Other dye markers, for example, PPD, have proven to be insufficient for adequate screening. ${ }^{3}$ Textile contact dermatitis is not uncommon, and may have inconspicuous presentations; positive results are usually clinically relevant. A high suspicion, correct clinical advice and better textile labelling are key points to improve diagnosis and management.

\section{Conflict of interest}

The authors declare no potential conflict of interests.

\section{ORCID}

Rita Ramos Pinheiro (D) http://orcid.org/0000-0002-1448-0362

Ana S. Borges (D) http://orcid.org/0000-0002-2965-5962

\section{REFERENCES}

1. Malinauskiene L, Bruze M, Ryberg K, Zimerson E, Isaksson M. Contact allergy from disperse dyes in textiles: a review. Contact Dermatitis. 2013;68:65-75.

2. Johansen JD, Aalto-Korte K, Agner T, et al. European Society of Contact Dermatitis guideline for diagnostic patch testing-recommendations on best practice. Contact Dermatitis. 2015;73:195-221.

3. Isaksson M, Ryberg K, Goossens A, Bruze M. Recommendation to include a textile dye mix in the European baseline series. Contact Dermatitis. 2015;73:15-20.

4. Portuguese Group for Contact Dermatitis Study. Disperse dyes. In: Aristegui B, ed. Interpretation of Positive Reactions in Patch Testing. 1st ed. Portugal: Aristegui Bial; 2015.

How to cite this article: Ramos Pinheiro R, Borges AS, Brasileiro A. Textile allergic contact dermatitis caused by occupational exposure-An overlooked condition. Contact Dermatitis. 2018;79:323-324. https://doi.org/10.1111/cod.13080 